\title{
INVESTIGATION OF SOCIAL BASED COOPERATIVES ON SOCIAL HEALTH OF FEMALE HEADED HOUSEHOLDS
}

\author{
Hoda Fotovvat \\ Faculty of Social Work, Tabatabayi University, Dehkadeh-ye-Olympic, Tehran, Iran
}

Received 2013-12-02; Revised 2013-12-03; Accepted 2014-01-09

\begin{abstract}
This study aims to evaluate the influence of participation in society-based cooperatives on social health of female households, which is an important factor in the life of these women. The statistical society of this research is all female headed households who have visited the Social Services Center of Region 3 of Tehran Municipality since early 2011. The participation of female headed households in group activities such as formation of cooperatives has shown strong effects on improving social health index. Among the indices of social health such as participation, integration and actualization, social acceptance is more matured indicating the influence of such activities on the growth of positive feeling on others and environment and it has an important role in developing the process of empowerment.
\end{abstract}

Keywords: Female Households, Social Health, Social Acceptance, Social Participation, Social Integration, Social Actualization

\section{INTRODUCTION}

A phenomenon called "Female Headed Households" is a social fact and there are many reasons why we now observe it in all societies. They are the most vulnerable people in any society. So, studying their life patterns and their difficulties is a goal for all devout and social sympathetic people who take on the humanistic challenges of helping others. This article has been compiled from the findings of some social researches about female headed households and it is of documentary and content analysis kind.

Research results show that female headed households confront with many problems and they experience a lot of physical, psychic and spiritual, social and cultural traumas.

\subsection{Cooperatives and Social Health}

Cooperatives are considered as a good lever for economic development and effective in the direction of governmental policies on improvement of live conditions, job opportunities, level of income and social conditions of people. Developed countries are following the aim of developing cooperative sector in order to renovate their old economic strategies and have more equitable socio-economic conditions (Aaron, 1992).

Cooperatives are formed under seven core principles in the world. These principles are indicators of the power of this part of economy in eliminating women's deprivation, female headed households in particular:

- Free and voluntarily membership and taking advantages of services and facilities of cooperatives to meet the common needs and goals

- Ruling of members

- Economic participation of members in achieving the goals

- Self-discipline and independence of cooperatives

- Training, apprenticeship and informing in cooperatives (continuous empowerment)

- Cooperation of cooperatives

- Caring about society issues

Studies reveal that cooperatives could have maintained their significant presences in all socio- 
economic stages as an undeniable fact since last two centuries. Based on these studies, the following lacks are regarded as the reasons for the inefficiency of cooperatives: Lack of recognition and exploitation of chances, lack of access to various resources, lack of creativity, innovation and value creating, lack of insight and prudence, lack of outlook and ability to see the distant horizons, lack of feeling independent, lack of perseverance, lack of ability to manage the social domains, lack of commitment and responsibility, lack of feel of risk taking and ability to manage and control the available and probable risks and lack of integrity (Mayer, 2008).

Health definition, namely being free from any physical sign of illness, has been a dominant model for studying and researching about the health. However, a change in illness-oriented approaches and emergence of healthbased approaches has extended further the concept and the meaning of health so that it encompasses a wide range of complete physical, mental and social well-being.

On the basis of such approach, health is not merely a goal but a source in our daily life to achieve other purposes and it would finally ends in growth of positive feeling about life and ability to self-recognition (Babaei, 2003).

In Geneva, (1948), the World Health Organization (WHO) offered a definition for health which can be still addressed by patterns of generality in health theories: "Health is a state of complete physical, mental and social well-being and not merely the absence of disease or infirmity".

In above definition, social health has been put beside physical and mental health for the first time. In definition of WHO, complete health means the ability to have an economic and socially generative life. As one of the health dimensions of human being, social health plays a key role in keeping social life balance and exhaustive development of it may result in social development.

In spite of the extensive researches carried out in some countries, many aspects have been remained unclear. For instance, social health has many parameters and dimensions which are different in countries and in some countries some parameters are more important than the other ones.

According to WHO, health is one of the core human rights and all men should have access to the constitutional resources. Understanding and identifying all sides of health urge all systems and structures having socio-economic conditions and physical environment under their control to consider the contents of their activities based on their effects on the society's and individuals' health and well-being.

What empirically lies at the root of the meaning of social health is sociological literature about social anomic and alienation.
Social health refers to how individuals communicate with others in the society or to their socialization. DorKim (2008) believes that if the relation between person and society is disconnected and he/she is not attracted to the social framework, the ground would be prepared for growth of social deviance. In such case, a kind of radical individualism would place individualistic wills against social life.

Social health includes various levels of social skills, social performance and the power of self-recognition as a member of a larger society. In general, any person is a member of a family and a larger society and his/her socio-economic conditions are considered in a network of social relations. Social health is rooted from a "positive material environment" (i.e., economic and residential subjects) and a "positive humanistic environment" which consider a particular social network.

Estes (1997) defines social health as conditions and well-being of individuals in a social relation network, including family, society and nation. Gey (1997) believes that by developing a sense of participation, involving individuals in social processes and encouraging people to spend time with their friends, to participate in social and career roles, to have religious activities and to have pleasure time with a group, social network positively influence individuals' health. Therefore, by providing new opportunities to be a member of social networks and participate in social events, social network plays significant roles such as career, family and parents roles and improves peoples' social health.

In 1998, Keyes stated that the lost ring in the history of health literature was answering to this question: Is it possible to evaluate the life quality and personal performance regardless of social standards? "Good performance is something more than physical and mental health and includes social challenges as well", he answered to this question and defined the concept of social health as follow: "Social health is in what way a person can evaluate his/her performance against the society".

A socially healthy person regards society as a meaningful, understandable and potentially developing setting and feels that he/she belongs to it, accepted by it and has share in its development. In fact, social health includes various elements and these elements together would show that how well individuals act and perform in their social lives as a neighbor, colleague.

MacArthur Foundation describes the operational definition of social health parameters as follow: The scale of social health has five dimensions, including. 


\subsection{Social Actualization}

Social actualization means assessing the potential power and evolving route of society and believing in this fact that the society is gradually maturing and have potential capabilities for a positive upheaval identified by social bodies and citizens. Healthy people are hopeful of their society's future. They are able to understand the collective powers and believe that they and other people can take advantage of these powers and their society's improvement. Social actualization is conceptually equivalent with self-realization and the growth of mental health. Self-developed people who determine their own fate see themselves as are continuously changing and have potential powers. They constantly seek to develop such powers. They believe that society has control over its fate and by its potential capabilities controls the route to development.

\subsection{Social Integration or Conformity}

Social integration or conformity is comparable with life meaninglessness and includes a conceivable, predictable and sensitive assessment. It is in fact a person's realization of quality, organization and management of social environment. Also, it means domination over environment in the scale of mental health. Domination over environment indicates a feeling of competence and capability for managing a complicated environment and choosing or creating proper personal settings. It contrasts with meaninglessness and purposelessness and means logically, smartly, conceivably and predictably watching the world. In societies in which the social connections and links are not in a desirable level and people prevent from sensible social correlations, the move toward forming and growing social wealth would be slow. Consequently, egoistic individualism would grow and social correlation would decrease. This draws people to social isolation and aloneness would spread all over the society. Such situation comes up with negative mental states in people.

\subsection{Social Solidarity}

Social solidarity occurs when a person assesses the quality of his/her relations in society and social groups. A healthy person feels that he/she is a part of a society and shares himself/herself with ones making the social reality. Kim believes that social health and unification reflects people's relations with others by norms. The meaning of social solidarity is placed against alienist and social isolation. Social alienisms mean a gap between a person and a society. It means rejecting society and believing in this fact that society does not reflect personal values and life styles. It also refers to breaking the personal supportive relations. Thus, a person with social solidarity feels closeness to his/her society and sees his/her group as a source of comfort and thrust. Thus, solidarity is a point in which people feel having something in common with people (e.g., neighbors) making the social reality and it is a point in which people feels that they belong to their society (Stones, 2000).

\subsection{Social Acceptance}

People having such dimension of health understand society as a general collection composed of different people. These people have a desirable viewpoint toward human's nature and feel comfort with others. Social acceptance is a paradigm of self-acceptance (one dimension of mental health). In case of self-acceptance, a person has a positive and good insight about self and his/her past life and accepts all self-aspects despite of weaknesses and incapability. Social acceptance helps a person believes and accepts their society and its people with all defects and positive and negative aspects.

People should work in this public domain with which they feel align. Ones who believe in social acceptance trust others. They think that other people deserve kindness and affection and believe that people can be skilled. They have various viewpoints about human's nature and feel comfort with other ones.

\subsection{Social Participation}

Social participation is a belief according to which the person knows him/herself as a critical member of the society and thinks that can be valuable for his/her it. Such people seek to be loved and share a world in which they are valued as human being. Social participation, parallel with life goals (having believes taking shape to the life), is considered as a scale of mental health as well. Social participation is similar to the concepts of responsibility and self-efficacy. Self-efficacy means that a person can have particular behaviors and destinations. Social responsibility means personal commitments against the society. Therefore, social participation is how much a person feels what he/she does is effective and valuable on the side of society and social well-being (Turner, 2008).

Keys prepared social health questionnaire on the basis of his theoretical model of social health. Analyzing confirmative factors, he confirmed the five-dimensional model applied in his questionnaire. This scale includes fifteen points: 3 points for social solidarity factor, 3 
points for social acceptance factor, 3 points for social participation factor and 3 points for social actualization and finally 3 points for social integration.

Based on the over mentioned subjects, this research seeks to answer the following question: "Have participating in the forming process of society-based cooperatives been effective in increasing the social health of experimental group"?

\section{MATERIALS AND METHODS}

This research is of pseudo-experimental kinds with single group pretest and posttest scheme. Such schemes are called pseudo-experimental because of incapability of researchers in controlling all important and effective factors in internal justifiability of experiment and particularly in not choosing random subjects from a broader society. Dependent variable is then measured before and after independent variables and includes the following stages:

- Performing pretests

- Exposing subjects to independent variables

- Performing posttests and comparing the results with a proper statistical tool for analyzing the information

Statistical society of the research is all female headed households referred to the social services center of region 3 of Tehran Municipality since early 2011 and included 198 female headed households.

Forty women were randomly selected and randomly divided into two 20 person experimental and 20 person evidence groups. Experimental group was provided with 10 educational sessions. Both groups participated in educational activities of the Social Services Center once in two weeks. Duration of divorcement and husband's deaths was at least 3 years and at most 8 years.

After sampling and dividing groups into society and evidence based cooperative formation groups, social health scale was initially implemented for both groups in October 2010. For experimental group then the educational-implementing process of forming societybased cooperatives was carried out for $3 \mathrm{~h}$ from 4 to 7 o'clock in the afternoon. Finally, two society-based cooperatives were registered by experimental groups and they started their primary activities.

In this research, data were analyzed by covariance analysis through sixteenth version of a statistical package for social sciences. In this analysis, membership in experimental and evidence groups is considered as privilege in scales and subscales of social health and as dependent variable. Two defaults of normality of score distribution and variance equality of groups in research variables were considered.

\section{RESULTS AND DISCUSSION}

Mean and standard deviation of pre and post test scores and their components in experimental and evidence groups have been presented in Table 1.

\section{CONCLUSION}

As it is seen in the Table $\mathbf{1}$, there is a significant difference between the mean scores of both groups. However, the difference is more significant in components of social acceptance, participation, integration, actualization and solidarity. This can be attributable to the influence of experimental variable.

Findings showed that after participating in the formation process of society-based cooperative, there would be a significant difference between two groups in case of social health. In other words, group and social activities may increase more the level of social health than evidence group.

The scale of social acceptance refers to the positive approach toward self and others. This result showed that female headed households' participation in group activities would cause the better acceptance of family and personal conditions and create the sense of self-development.

Table 1. Test Results of pre and post scores in two groups

\begin{tabular}{|c|c|c|c|c|c|c|c|c|c|c|}
\hline \multirow[b]{3}{*}{$\mathrm{P}$} & \multirow{3}{*}{$\begin{array}{l}\text { Means } \\
\text { differences }\end{array}$} & \multicolumn{4}{|c|}{ The control group } & \multicolumn{4}{|c|}{ Groups of community-based cooperatives } & \multirow{3}{*}{$\begin{array}{l}\text { Social health } \\
\text { and ITS }\end{array}$} \\
\hline & & \multicolumn{2}{|c|}{ Post test } & \multicolumn{2}{|c|}{ Post test } & \multicolumn{2}{|c|}{ Post test } & \multicolumn{2}{|c|}{ Post test } & \\
\hline & & M & SD & M & SD & M & SD & M & SD & \\
\hline $0 / 001$ & 7.029 & $8 / 56$ & $94 / 7$ & $9 / 87$ & $94 / 85$ & $7 / 7$ & $102 / 25$ & $8 / 35$ & $95 / 45$ & Social acceptance \\
\hline 0/001 & 3.717 & $7 / 49$ & $46 / 2$ & $7 / 92$ & $47 / 35$ & $6 / 16$ & $50 / 15$ & $6 / 78$ & $47 / 6$ & Social cooperation \\
\hline 0/001 & 1.044 & $1 / 71$ & $10 / 05$ & $2 / 365$ & $9 / 38$ & $1 / 5$ & $10 / 6$ & $2 / 46$ & $9 / 5$ & Social cohesion \\
\hline 0/001 & 2.648 & 2 & $24 / 4$ & 2 & $23 / 9$ & $1 / 39$ & $27 / 05$ & $2 / 31$ & $24 / 1$ & Social integration \\
\hline 0/001 & 3.290 & $3 / 30$ & $14 / 55$ & $3 / 62$ & $13 / 95$ & $3 / 8$ & 17.54 & $3 / 21$ & $14 / 25$ & Social actualization \\
\hline
\end{tabular}


In addition to implementing the process of occupation and empowerment of female headed households, participating in such activities improve the parameters of mental and social health due to their group-based and group dynamic characteristics.

According to the research results, providing a proper ground for female headed households to participate in group and society based activities and involve in other activities besides other women by responsible organizations, NGOs and welfare centers is regarded as an effective step in empowering them.

This research is also done by Rafi et al. (2013), in which they indicated that the remainder of resources and the perceived severity of health risk were the main factors and women's personal and socio-economic characteristics were the contextual factors involved in the health promotion activities of the participants. However they have focused more on economic condition but they also have resulted in a positive relationship between participation and social health of female headed households.

Thus, cooperatives have a good structure for training and occupation of female headed households resulting in women's empowerment, self-efficacy and self-reliance. They decrease the state of being discouraged, facilitate their presence in economic area of the society and provide an environment with comfort and pleasantness.

This research is been face with limitations in accessing the data, so for the future researched it should be focused in a bigger sample from all part of a city or provinces to show a more reliable result.

\section{REFERENCES}

Aaron, R., 1992. Basic Stages of Thought in Sociology. 3rd Edn., Parham, Tehran, pp: 345.

Babaei, N., 2003. Social Health Needs on the Ground of Social Changes. Social Well-Being Seasonally.

DorKim, E., 2008. About Division of Social Labor, Translated by Bagher Parham. 3rd Edn., Markaz Publication, Tehran.

Estes, R.J., 1997. Social Work, social development and community welfare centers in international perspective. Int. Soc. Work, 40: 43-55. DOI: 10.1177/002087289704000104

Gey, R., 1997. Sociology of Talcott Parsons. 1st Edn., Tabyan, Tehran.

Mayer, S.E., 2008. Building Community Capacity: The Potential of Community Foundations. 1st Edn., Rainbow Research, Sociology of Talcott Parsons, ISBN-10: 0962442844, pp: 222.

Rafi, F., N. Seyedfatemi and M. Rezaei, 2013. Factors involved in Iranian women heads of household's health promotion activities: A grounded theory study. J. Nurs., 7: 133-141. DOI: 10.2174/1874434601307010133

Stones, R., 2000. Prominent Thinkers of Sociology. 1st Edn., Trans, Mirdamadi, pp: 2.

Turner, J., 1998. Sociology Theorization, Translated by Abdolali Lahestani Zadeh. 1st Edn., Navid Shiraz, Shiraz. 